\title{
Corticotropin-releasing Factor in the Rat Dorsal Raphe Nucleus Promotes Different Forms of Behavioral Flexibility Depending on Social Stress History
}

\author{
Kevin P Snyder', Tiffany E Hill-Smith ${ }^{2}$, Irwin Lucki ${ }^{2,3}$ and Rita J Valentino*,4 \\ 'Neuroscience Graduate Group, University of Pennsylvania, Philadelphia, PA, USA; ${ }^{2}$ Department of Psychiatry, University of Pennsylvania, \\ Philadelphia, PA, USA; ${ }^{3}$ Department of Pharmacology, University of Pennsylvania, Philadelphia, PA, USA; ${ }^{4}$ Department of Anesthesiology, The \\ Children's Hospital of Philadelphia, Philadelphia, PA, USA
}

\begin{abstract}
The stress-related neuropeptide, corticotropin-releasing factor (CRF) regulates the dorsal raphe nucleus-serotonin (DRN-5-HT) system during stress and this may underlie affective and cognitive dysfunctions that characterize stress-related psychiatric disorders. CRF acts on both $\mathrm{CRF}_{1}$ and $\mathrm{CRF}_{2}$ receptor subtypes in the DRN that exert opposing inhibitory and excitatory effects on DRN-5-HT neuronal activity and $5-\mathrm{HT}$ forebrain release, respectively. The current study first assessed the cognitive effects of intra-DRN microinfusion of CRF or the selective $\mathrm{CRF}_{2}$ agonist, urocortin II in stress-naive rats on performance of an operant strategy set-shifting task that is mediated by the medial prefrontal cortex (mPFC). CRF (30 ng) facilitated strategy set-shifting performance, whereas higher doses of CRF and urocortin II that would interact with $\mathrm{CRF}_{2}$ were without effect, consistent with a $\mathrm{CRF}_{1}$-mediated action. This dose decreased 5-HT extracellular levels in the mPFC, further supporting a role for $\mathrm{CRF}_{\mathrm{I}}$. The effects of CRF were then assessed in rats exposed to repeated social stress using the resident-intruder model. Repeated social stress shifted the CRF effect from facilitation of strategy set shifting to facilitation of reversal learning and this was most prominent in a subpopulation of rats that resist defeat. Notably, in this subpopulation of rats 5-HT neuronal responses to CRF have been demonstrated to shift from $\mathrm{CRF}_{1}$-mediated inhibition to $\mathrm{CRF}_{2}$-mediated excitation. Because 5-HT facilitates reversal learning, the present results suggest that stress-induced changes in the cellular effects of CRF in the DRN translate to changes in cognitive effects of CRF. Together, the results underscore the potential for stress history to shift cognitive processing through changes in CRF neurotransmission in the DRN and the association of this effect with coping strategy.

Neuropsychopharmacology (20I5) 40, 25 I7-2525; doi:I0.I038/npp.20I5.98; published online 6 May 2015
\end{abstract}

\section{INTRODUCTION}

Stress is associated with psychiatric disorders that are characterized by alterations of mood and cognition (Gold and Chrousos, 2002; Kessler, 1997; McEwen, 2003). This association is based in part on the ability of stress to modulate monoamine neurotransmitter systems, such as the locus coeruleus (LC)-norepinephrine (NE) system and the dorsal raphe nucleus (DRN)-serotonin (5-HT) system. These systems project to higher order limbic and forebrain regions that regulate mood and cognition (Fox and Lowry, 2013; Maier and Watkins, 2005; Valentino and Van Bockstaele, 2008).

Stress alters activity of the LC-NE and DRN-5-HT systems in part through the stress-related neuropeptide, corticotropin-releasing factor (CRF) (Fox and Lowry, 2013; Maier and Watkins, 2005; Valentino and Commons, 2005;

\footnotetext{
*Correspondence: Dr RJ Valentino, Department of Anesthesiology, The Children's Hospital of Philadelphia, 402D Abramson Pediatric Research Center, Philadelphia, PA 19104, USA, Tel: + 215590 0650, Fax: + I 215590 3364, E-mail: valentino@email.chop.edu

Received 16 September 2014; revised 6 February 2015; accepted 2 March 2015; accepted article preview online 13 April 2015
}

Valentino and Van Bockstaele, 2008). Through CRF actions on monoamine-forebrain projecting neurons, stressors can modulate activity in forebrain structures that regulate cognitive functions. Stressors and CRF have been reported to exert both excitatory and inhibitory effects on the DRN-5HT system (Kirby et al, 2000, 1997; Valentino and Commons, 2005). This complexity derives in part from the expression of both $\mathrm{CRF}_{1}$ and $\mathrm{CRF}_{2}$ receptor subtypes in the DRN that exert opposing inhibitory and excitatory effects on DRN-5-HT neuronal activity and 5-HT forebrain release, respectively (Lukkes et al, 2008; Pernar et al, 2004; Valentino and Commons, 2005). Relatively low CRF concentrations engage $\mathrm{CRF}_{1}$ resulting in neuronal inhibition and decreased 5-HT release, whereas higher CRF concentrations activate $\mathrm{CRF}_{2}$ to excite 5-HT neurons and increase 5-HT release (Kirby et al, 2000; Lukkes et al, 2008; Price and Lucki, 2001). Certain behavioral consequences of acutely activating different CRF receptors in the DRN have been examined and related to affective symptoms of psychiatric disorders (Hammack et al, 2003a, 2002; Meloni et al, 2008). However, the cognitive consequences have been less well studied. 
CRF effects on DRN-5-HT neurons are also determined by stress history, which influences the cellular distribution of $\mathrm{CRF}_{1}$ and $\mathrm{CRF}_{2}$. For example, following swim stress $\mathrm{CRF}_{2}$ is recruited to the plasma membrane and $\mathrm{CRF}_{1}$ becomes internalized, resulting in a qualitative shift in neuronal responses to CRF from inhibition to excitation (Waselus et al, 2009). Repeated social stress produces a similar redistribution of CRF receptors and shift in neuronal response to CRF selectively in a subpopulation of rats that resist defeat (Wood et al, 2013). Stress-induced changes in CRF receptor cellular localization and neuronal responses could translate to qualitative changes in behavioral or cognitive responses to CRF.

The current study first assessed the cognitive impact of activating DRN CRF ${ }_{1}$ and $\mathrm{CRF}_{2}$ receptors on performance of a PFC-dependent operant strategy set-shifting task (OSST) (Floresco et al, 2008) in stress-naïve rats. This task assesses two different forms of cognitive flexibility, reversal learning and strategy shifting. Because social stress is a prevalent stressor for humans and has been demonstrated to shift the distribution of $\mathrm{CRF}_{1}$ and $\mathrm{CRF}_{2}$ receptors in DRN neurons in a subpopulation of rats that exhibit a particular coping strategy, the ability of this stressor to modify the cognitive effects of CRF in the DRN and the association of this effect with coping style were then examined (Wood et al, 2013).

\section{MATERIALS AND METHODS}

\section{Animals}

Male adult Sprague Dawley rats (275-300 g, Charles River, Wilmington, Massachusetts) were subjects of behavioral testing. Male Long Evans retired breeder rats (550-850 g, Charles River) were residents in the resident-intruder social stress. Rats were singly housed on a $12 \mathrm{~h}$ light/dark cycle with lights on at 0700 hours and given at least 4 days to acclimate to the colony before experimentation began. Care and use of animals was approved by the Institutional Animal Care and Use Committee of the Children's Hospital of Philadelphia.

\section{Surgery}

Rats were anesthetized with isoflurane (2\%) and positioned in a stereotaxic instrument for implantation of a cannula guide in the DRN (Price and Lucki, 2001). For microdialysis experiments, animals were also implanted with a cannula guide (20 gauge) in the medial prefrontal cortex (mPFC) with the following coordinates relative to bregma: AP $+3.2 \mathrm{~mm}, \mathrm{ML}+0.6 \mathrm{~mm}$, and DV $2.5 \mathrm{~mm}$ below the skull surface. Rats were assigned to one of the three experimental protocols: (1) OSST, (2) social stress followed by OSST or (3) microdialysis. Rats that were trained and tested in the OSST began food restriction to maintain $85 \%$ of their weight 3 days prior to the start of training. For rats in the social stress experiment, food restriction began the day after the last stress or control manipulation.

\section{Operant Training and Testing}

Training and testing of the OSST was identical to that previously described (Snyder et al, 2014) and modified from the original procedure described by Floresco et al (2008); see
Supplementary Information for details. Rats were first trained to press one of two levers for food reinforcement on the first training day and the opposite lever on the following day. On the third training day one of the two levers was randomly selected to deliver reward one, three, or five trials in a row, such that over many trials both levers were equally likely to deliver a reward. The following day was the test day and rats received an intra-DRN infusion of either ACSF, CRF (10-100 ng per $200 \mathrm{nl}$ ), or urocortin II (100 ng per $200 \mathrm{nl}$ ) over a 1 min period using tubing attached to a Hamilton syringe delivered by a syringe pump $10 \mathrm{~min}$ prior to behavioral testing. This concentration of urocortin II was chosen as one that has been shown to be selective for $\mathrm{CRF}_{2}$ receptors in the DRN based on electrophysiological and microdialysis studies (Amat et al, 2004; Pernar et al, 2004). The OSST consisted of a series of three consecutive discriminations: an initial side discrimination (SD), a side reversal (SR) discrimination, and a shift to light discrimination (LD). Animals proceeded from one stage of the task to the next after achieving a criterion of 8 consecutive correct choices, providing that 30 trials had been attempted. The $30-$ trial minimum criterion was stipulated to ensure that each animal completed the same minimum number of trials in each stage of the task. On each trial only one stimulus light was illuminated. For every pair of trials, the left or right stimulus light was randomly selected to be illuminated on the first trial and the opposite stimulus light was illuminated on the following trial. During the SD stage, the lever on the side opposite the animal's side bias was designated to be the correct lever on every trial, regardless of the location of the stimulus light. During the SR stage, the correct lever on each trial was designated to be the lever opposite the correct lever during the initial SD. During the LD stage, the correct lever was designated as the lever underneath the illuminated stimulus light on each trial. After reaching criterion in the LD stage, the task ended and the animal was removed from the chamber.

Trials to criterion (TTC) were recorded during each stage of the OSST. Omitted trials were not included in the TTC measure. Error types within both the SR and LD stages of the OSST were characterized using logistic regression to determine whether treatments impacted perseveration of the previous rule or the acquisition and maintenance of the new rule (see Supplementary Information; Snyder et al, 2014).

\section{Social Stress}

Social stress using the resident intruder model was identical to that previously described (Wood et al, 2013) and modified from the model developed by Miczek (1979). The stress or control manipulation was initiated at least 5 days after recovery from surgery. Briefly, intruder rats were placed into the cage of a resident rat and were allowed to interact until a defeat had occurred, as defined by the intruder assuming a submissive supine posture for at least $3 \mathrm{~s}$, or $15 \mathrm{~min}$ had elapsed. The rats were then separated by a wire mesh barrier for the remainder of a 30-min session, after which rats were returned to the home cage. This was repeated for 5 consecutive days with the intruder rat being exposed to a different resident on each day. The average latency to defeat across all five sessions was calculated for each intruder and subjected to cluster analysis to identify subpopulations as 
defined by different propensities to defeat. Control rats were placed in novel cages for $30 \mathrm{~min}$ for 5 consecutive days. Rats began food restriction to $85 \%$ free-feeding weight after the last session and behavioral training for the OSST began 3 days later.

\section{Microdialysis}

Custom concentric-style dialysis probes were constructed as previously described (Kirby et al, 1997). Four hours before the experiment was conducted, rats were briefly anesthetized with isoflurane $(2 \%)$ and a dialysis probe was inserted into the $\mathrm{mPFC}$ and secured with cranioplastic cement. Rats were then placed into one of the experimental chambers used for the OSST (described above) and the probe was connected to a liquid swivel and spring with a counterbalanced arm attached to allow free movement (Instech Laboratories, Plymouth Meeting, PA). Filtered artificial cerebrospinal fluid (ACSF) $\left(147 \mathrm{mM} \mathrm{NaCl}, 1.7 \mathrm{mM} \mathrm{CaCl} 2,0.9 \mathrm{mM} \mathrm{MgCl}_{2}\right.$, and $4 \mathrm{mM} \mathrm{KCl}, \mathrm{pH}$ 6.3-6.5) was continuously perfused at a rate of $0.8 \mu \mathrm{l} / \mathrm{min}$ using a syringe pump (KD Scientific, Holliston, MA). After $4 \mathrm{~h}$ of recovery time, baseline dialysate samples were collected every $20 \mathrm{~min}$ for $2 \mathrm{~h}$ prior to infusions.

After collecting baseline dialysate samples, each rat received a $200 \mathrm{nl}$ intra-DRN infusion of either ACSF or CRF (30 ng) over a 1-min period using tubing attached to a Hamilton syringe and a syringe pump. Dialysate samples continued to be collected post-infusion every $20 \mathrm{~min}$ for 2 more hours into polypropylene microcentrifuge vials (Fisher Scientific, Pittsburgh, PA) and stored at $-70^{\circ} \mathrm{C}$ until analyzed via high-pressure liquid chromatography. The first two baseline sample collections were discarded from analysis. The first sample collected after infusion was also discarded from analysis to allow time for dialysate in the line to clear and not interfere with the post-infusion dialysis results. Analysis of dialysates for 5-HT and dopamine (DA) was performed as previously described (see Supplementary Information; Andrews and Lucki, 2001).

\section{Histology}

At the end of each experiment, pontamine sky blue dye $(200 \mathrm{nl})$ was infused into the DRN cannula of each rat and brains were removed, frozen in isopentane, and stored at $-80^{\circ} \mathrm{C}$. Brains were sectioned $(30 \mu \mathrm{m}$-thick) on a cryostat and mounted on charged slides (Fisher Scientific). Sections were stained with neutral red and coverslipped for visualization of pontamine sky blue in the DRN. For microdialysis experiments, the dialysis probe tract was also localized. Only rats with accurate placement of the infusion cannulae and dialysis probe in the targeted neuronal structures were used in the data analysis.

\section{Statistical Analysis}

Effects of treatment on TTC were assessed by means of a twoway ANOVA (treatment $\times$ stage) with repeated measures across stage. Effects of treatment on error type during the SR and shift to light stages were analyzed by one-way ANOVAs.

Absolute values (picogram) of 5-HT and DA from each 20 min microdialysis collection were normalized by dividing each value by the average of the four baseline collection values. Effects of ACSF vs CRF treatment were compared by two-way ANOVA (treatment $\times$ time) with repeated measures across time. For comparison of ACSF or CRF treatment response to baseline, the baseline collection time points were averaged and normalized to a single data point of $100 \%$ and a one-way ANOVA was performed with repeated measures across time within each treatment group. Follow-up comparisons were conducted using Fisher's LSD test.

As previously described (Wood et al, 2013), a cluster analysis (JMP 9.0; SAS, Cary, North Carolina) of defeat latencies was used to categorize animals based on their stress-coping strategy. Two clusters were generated for each group, and animals were classified as either short (SL) or long latency (LL) animals. To examine the dependency of the effect CRF treatment on coping style, identical analyses of TTC and error type as described above were performed on these subpopulations. Where significant main effects or interactions were found, follow-up post-hoc comparisons were performed using the Student-Newman-Keuls method, unless otherwise noted.

\section{Drugs}

Ovine CRF and urocortin II (American Peptide Company, Sunnyvale, CA) were dissolved in water and $10 \mu \mathrm{g}$ aliquots were concentrated and kept at $-80^{\circ} \mathrm{C}$ until dilution into ACSF on the day of the experiment. Ovine CRF was used because of its greater selectivity for $\mathrm{CRF}_{1}$ compared with rat CRF (Hauger et al, 2003).

\section{RESULTS}

\section{Effects of Intra-DRN CRF and Urocortin II on Cognitive Performance of Stress-Naive Rats}

Of 19 rats administered ACSF into the DRN, 17 completed the entire task. As expected, ACSF-treated rats required more trials to reach criterion in the strategy set-shifting stage of the task compared with other components (Figure 1). A repeated measures ANOVA indicated a within-subject effect of stage $(\mathrm{F}(2,15)=5.2, p=0.02)$. Of 29 rats administered CRF into the DRN, 28 completed the entire task. The one rat that did not complete the task was administered a $100 \mathrm{ng}$ dose of CRF.

Intra-DRN CRF produced biphasic dose-dependent effects on task performance (Figure 1). There was a trend toward a between-subject effect of treatment $(F(3,40)=2.7, p=0.06)$ and a significant within-subject treatment $\times$ stage interaction $(\mathrm{F}(6,80)=2.4, p<0.05)$. Post-hoc comparisons revealed that the $30 \mathrm{ng}$ dose of CRF significantly improved strategy setshifting performance (LD) as compared with ACSF (Figure 1). This effect was not apparent when the dose was increased to $100 \mathrm{ng}$. Analysis of error type revealed no significant effects of treatment during either reversal learning (SR) or strategy set-shifting (LD) (Supplementary Table S1).

The behavioral effects of CRF (30 ng) were regionally limited to the DRN (Figure 2). CRF (30 ng) injections that were located outside of the DRN had no effect on strategy set-shifting performance (Figure 2). A two-way repeated measures ANOVA showed a between-subject effect of injection $(\mathrm{F}(2,40)=6.2, \quad p<0.005)$ and a within-subject injection $\times$ stage interaction $\quad(F(4,78)=2.62, \quad p<0.05)$. 


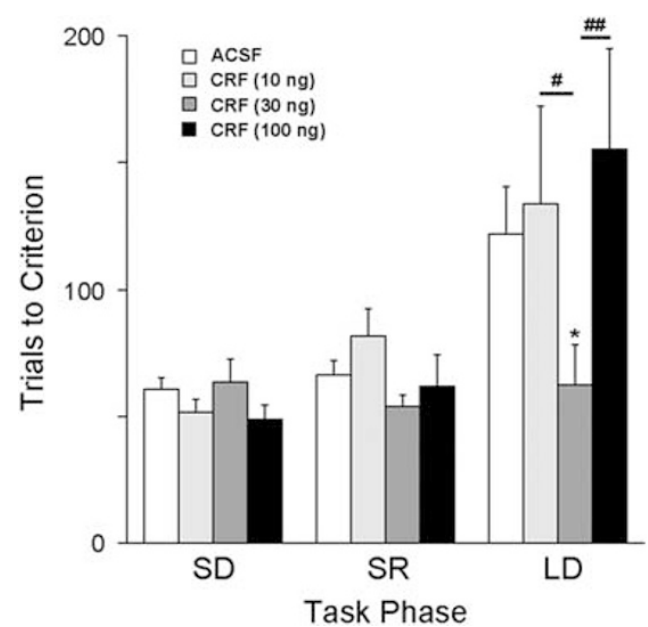

Figure I Intra-DRN-administered CRF (30 ng) facilitates strategy setshifting performance. The ordinate indicates task performance as the number of trials to reach criterion. The abscissa indicates the task phase: side discrimination (SD), side reversal discrimination (SR), and shift to light discrimination (LD). The number of rats for each group was: ACSF $(n=17)$, CRF I $0 \mathrm{ng}(n=6), \mathrm{CRF} 30 \mathrm{ng}(n=13)$, and CRF I00 ng $(n=8)$. Vertical lines indicate SEM. ${ }^{*} p<0.05$, compared with ACSF; $\#_{p}<0.05$, \# $p<0.0$ I, compared with other CRF doses. ACSF, artificial cerebrospinal fluid; CRF, corticotropin-releasing factor; DRN, dorsal raphe nucleus.

Post-hoc comparisons revealed that rats administered CRF $(30 \mathrm{ng})$ outside of the DRN did not perform significantly differently than ACSF-treated rats and performed significantly worse in the strategy set-shifting phase (LD) than rats receiving CRF (30 $\mathrm{ng}$ ) in the DRN (Figure $2 \mathrm{c}$ ).

Administration of Urocortin II (100 ng), a selective $\mathrm{CRF}_{2}$ agonist had no effect on performance in any phase of the task as indicated by a two-way repeated measures ANOVA (between subject effect of treatment: $\mathrm{F}(1,21)=0.35, p=0.6$; within-subject treatment $\times$ stage interaction: $\mathrm{F}(2,20)=0.58$, $p=0.6$ ) (Figure 3 ). Moreover, analysis of error type during both the reversal learning and strategy set-shifting task phases did not reveal any significant treatment-related effects (Supplementary Table S1).

\section{Impact of Intra-DRN CRF on 5-HT and DA Release in the mPFC}

The dose of CRF that improved strategy set-shifting performance produced an overall decrease in 5-HT extracellular levels in the $\mathrm{mPFC}$, consistent with activation of $\mathrm{CRF}_{1}$ in the DRN (Lukkes et al, 2008) (Figure 4a). A two-way repeated measures ANOVA revealed a trend for a significant between-subject effect of treatment $(\mathrm{F}(1,13)=4.3, p=0.059)$ and a within-subject treatment $\times$ time interaction $(\mathrm{F}(8,6)=6.5$, $p<0.02)$. Comparison of post-infusion time points to baseline levels revealed significant deviations below baseline in CRF-treated rats at $40(p<0.05), 80(p<0.05)$, and $100 \mathrm{~min}$ $(p<0.01)$ while no significant deviations from baseline levels were found in ACSF-treated rats. Notably, this decrease is most apparent during the approximate time that strategy set-shifting performance would be assessed. In contrast to its effects on 5-HT, CRF had no effect on mPFC DA release in the same subjects (between-subject efffect of treatment: $\mathrm{F}(1,13)=0.06, p=0.8$; within-subject treatment $\times$ time interaction: $\mathrm{F}(8,6)=0.67, p=0.7)$ (Figure $4 \mathrm{~b})$.

\section{Impact of Prior Social Stress Experience on the Cognitive Effects of Intra-DRN CRF}

In rats with a history of social stress, CRF (30 ng) also altered OSST performance compared with ACSF. A repeated measures ANOVA revealed no between-subject effect of treatment $(\mathrm{F}(1,21)=1.9, p=0.18)$ but a treatment $\times$ stage interaction $(\mathrm{F}(2,20)=4.2, p<0.05)$. Notably, in contrast to unstressed rats, CRF improved reversal learning performance rather than strategy set-shifting performance (Figure 5a). Analysis of error type during reversal learning revealed that CRF-treated rats made fewer regressive errors $(11 \pm 2.5)$ than ACSF-treated rats $(20 \pm 3, p<0.05)$. CRF did not affect the number of perseverative errors made during reversal learning. There was no effect of treatment on error type during strategy set-shifting (See Supplementary Table S1 for detailed statistics of error type analysis).

As previously reported (Wood et al, 2010), rats exposed to repeated social stress clustered into two populations based on their latency to assume the defeat posture, with a mean latency of $305 \mathrm{~s} \pm 24 \mathrm{~s}$ for SL rats $(n=13)$ and a mean latency of $560 \pm 20 \mathrm{~s}$ for LL rats $(n=14)(p<0.001)$. Analyzing CRF effects with respect to coping style revealed that social stress shifted the CRF response from improvement of strategy shifting to improvement of reversal learning selectively in LL rats (Figure 5b). There was no between-subject effect of group $(\mathrm{F}(2,20)=1.6, p=0.2)$ but there was a group $\times$ stage interaction $(\mathrm{F}(4,38)=2.74, p<0.05)$ and post-hoc tests showed a statistically significant effect of CRF to decrease TTC during the reversal stage for LL rats selectively (F $(2,20)=3.75, p<0.05)$. ACSF SL and LL rats were pooled as the comparison between these subpopulations showed no effect of latency $(\mathrm{F}(1,7)=0.15, p=0.7)$ or latency $\times$ stage interaction $(F(2,6)=0.7, p=0.5)$. There was a trend for a decrease in regressive errors in the CRF-treated LL rats although this was not statistically significant $(\mathrm{F}(2,20)=3.1$, $p=0.07)$. Although it appeared that the CRF-related improvement of strategy shifting was selectively maintained in the SL rats, this was not statistically significant $(\mathrm{F}(2,20)=1.6$, $p=0.2$.

\section{DISCUSSION}

The current study identified a novel effect of CRF in the DRN of stress-naive rats to facilitate cognitive flexibility as measured by strategy set-shifting. Convergent lines of evidence suggested that this effect was mediated by $\mathrm{CRF}_{1}$ receptors because it was produced by a moderate dose of CRF that interacts with $\mathrm{CRF}_{1}$ receptors, but not by a higher dose or by urocortin II, a peptide that is selective for $\mathrm{CRF}_{2}$ receptors (Reyes et al, 2001). In addition, the behaviorally effective CRF dose decreased forebrain extracellular 5-HT levels, consistent with $\mathrm{CRF}_{1^{-}}$and not $\mathrm{CRF}_{2}$-mediated responses (Forster et al, 2008; Lukkes et al, 2008; Price and Lucki, 2001). Importantly, in a subpopulation of rats in which social stress has been shown to redistribute $\mathrm{CRF}_{1}$ and $\mathrm{CRF}_{2}$ receptors so that $\mathrm{CRF}_{2}$ is more prominent on the plasma membrane, the effects of CRF shifted from 
a
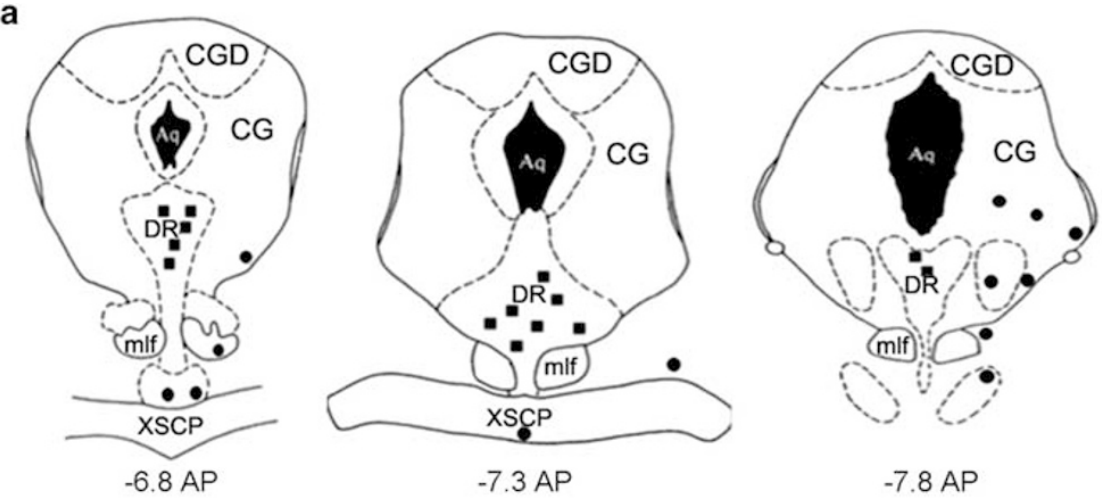

b

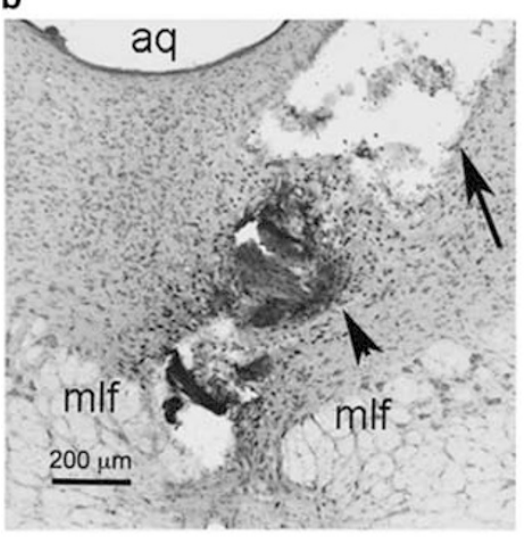

C

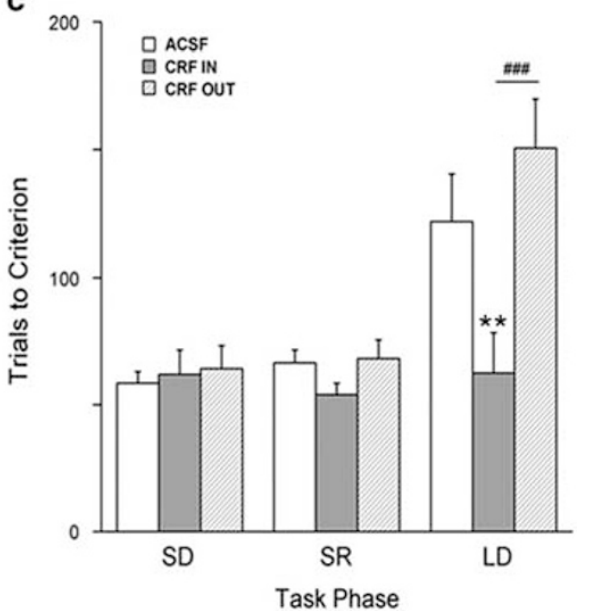

Figure 2 Facilitation of strategy set-shifting by intra-DRN CRF (30 ng) is regionally specific. (a) Location of 30 ng CRF infusions in (solid squares) and outside (solid circles) of the DRN. The location of infusions was reconstructed onto plates 47, 49, and 5 I (left to right) from the Atlas of Paxinos and Watson, (I998). The distance posterior to Bregma is indicated under each plate. Aq, cerebral aqueduct; CG, central gray; CGD, central gray, dorsal; DR, dorsal raphe nucleus; mlf, medial longitudinal fasciculus; xscp, decussation of the superior cerebellar peduncle. (b) Photomicrograph showing the DRN of a representative animal that was injected with CRF. The cannula tract (arrow) and dye (arrowhead) show histological verification of the injection site in the DRN. aq =aqueduct, $\mathrm{mlf}=$ medial longitudinal fasciculus. (c) Task performance indicated by the number of trials to reach criterion for rats that received ACSF or CRF inside or outside of the DRN. The number of rats for each group was ACSF $(n=17)$, CRF 30 ng in $(n=13)$, and CRF 30 ng out $(n=13)$. Vertical lines indicated SEM. ${ }^{*} *$ $p<0.02$ compared with ACSF, \#\#\# $p<0.002$ compared with other CRF treatment group. ACSF, artificial cerebrospinal fluid; CRF, corticotropin-releasing factor; DRN, dorsal raphe nucleus.

facilitation of strategy set-shifting to facilitation of reversal learning (Wood et al, 2013). This is consistent with $\mathrm{CRF}_{2}-$ mediated increases in DRN-5-HT activity and the role of 5HT in reversal learning (Clarke et al, 2004; Pernar et al, 2004). Together the results suggest that acute stress can have distinct cognitive consequences depending on social stress history and individual coping strategy as a result of CRF interactions with the DRN-5-HT system.

\section{Behavioral Effects of CRF in the DRN}

The DRN is densely innervated by CRF and CRF axon terminals here synapse with both 5-HT and non-5-HT (eg, GABA) dendrites (Valentino et al, 2001; Waselus et al, 2005). In situ hybridization studies suggest that $\mathrm{CRF}_{2}$ is the prominent CRF receptor subtype in the DRN (Day et al, 2004). However, studies using pharmacological manipulation of CRF receptors in the DRN to examine electrophysiological, microdialysis, and behavioral endpoints provided evidence for effects mediated by both $\mathrm{CRF}_{1}$ and $\mathrm{CRF}_{2}$ receptors (Hammack et al, 2003a,b; Kirby et al, 2000, 2008; Lukkes et al, 2008; Pernar et al, 2004). In general, these studies suggest that low levels of CRF, as might be released with acute mild stress, activate $\mathrm{CRF}_{1}$ receptors on GABAergic neurons to inhibit 5-HT neuronal activity and release in forebrain regions (Kirby et al, 2000, 2008; Price and Lucki, 2001; Roche et al, 2003; Waselus et al, 2005). In contrast, this inhibition is lost as the dose of CRF is increased to interact with $\mathrm{CRF}_{2}$ receptors (Kirby et al, 2000; Price and Lucki, 2001). The behavioral effects of engaging $C_{2 R}$ and $C_{1} F_{2}$ receptors in the DRN have been well characterized in the model of learned helplessness (Hammack et al, 2003a,b; Maier and Watkins, 2005). In this model, $\mathrm{CRF}_{2}$-induced activation of DRN-5-HT neurons and 5-HT forebrain release were associated with deficits in learning a shock escape task. In contrast, $\mathrm{CRF}_{1}$-mediated inhibition of the DRN-5HT system prevented the production of learned helplessness by a $\mathrm{CRF}_{2}$ agonist or uncontrollable stress. Thus, the opposing neuronal effects associated with $\mathrm{CRF}_{1}$ and $\mathrm{CRF}_{2}$ translate to opposing behavioral responses. 
Although the role of CRF in the DRN in learned helplessness has been well characterized, its ability to regulate cognitive functions in the absence of fear-related stimuli through the DRN system have not been previously examined.

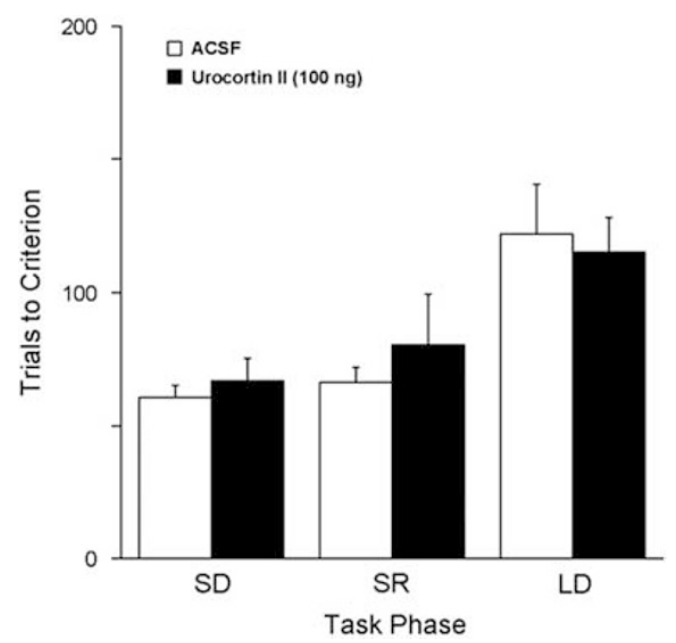

Figure 3 Intra-DRN administration of the selective $\mathrm{CRF}_{2}$ agonist Urocortin II did not affect task performance. Task performance indicated by the number of trials to reach criterion. Each bar is the mean of 17 ACSFtreated rats and 6 urocortin II-treated rats. Vertical lines indicated SEM. ACSF, artificial cerebrospinal fluid; CRF, corticotropin-releasing factor; DRN, dorsal raphe nucleus.

\section{Facilitation of Strategy Set-Shifting Performance Mediated by $\mathrm{CRF}_{1}$ not $\mathrm{CRF}_{2}$}

A major finding of this study was that CRF, regionally localized to the DRN, facilitated strategy set-shifting performance with an inverted U-shaped dose-response relationship. This resembles dose-response relationships for CRF effects on DRN-5-HT neuronal activity and 5-HT extracellular levels in forebrain measured by microdialysis (Kirby et al, 2000; Lukkes et al, 2008; Price and Lucki, 2001). The effective CRF dose (30 ng) for facilitation of strategy setshifting was one that produces the characteristic $\mathrm{CRF}_{1}$ mediated inhibition of 5-HT DRN neurons in unstressed rats (Wood et al, 2013). The finding that raising the CRF dose to $100 \mathrm{ng}$ or administering urocortin II failed to facilitate setshifting performance is consistent with its mediation by $\mathrm{CRF}_{1}$ and not $\mathrm{CRF}_{2}$ receptors. Several studies have found that high doses of CRF in the DRN preferentially activate $\mathrm{CRF}_{2}$ receptors and produce physiological effects that are opposite to those produced by lower doses acting on $\mathrm{CRF}_{1}$ receptors (Fox and Lowry, 2013; Lukkes et al, 2008; Valentino and Commons, 2005). The microdialysis results indicated that the behaviorally active dose of CRF (30 ng) decreased 5-HT extracellular levels in the MPFC at a time when behavior would be measured. This result is consistent with the known inhibitory effects of $\mathrm{CRF}_{1}$ receptor activation on 5-HT release in various forebrain regions and provides additional evidence that the facilitation of strategy set-shifting
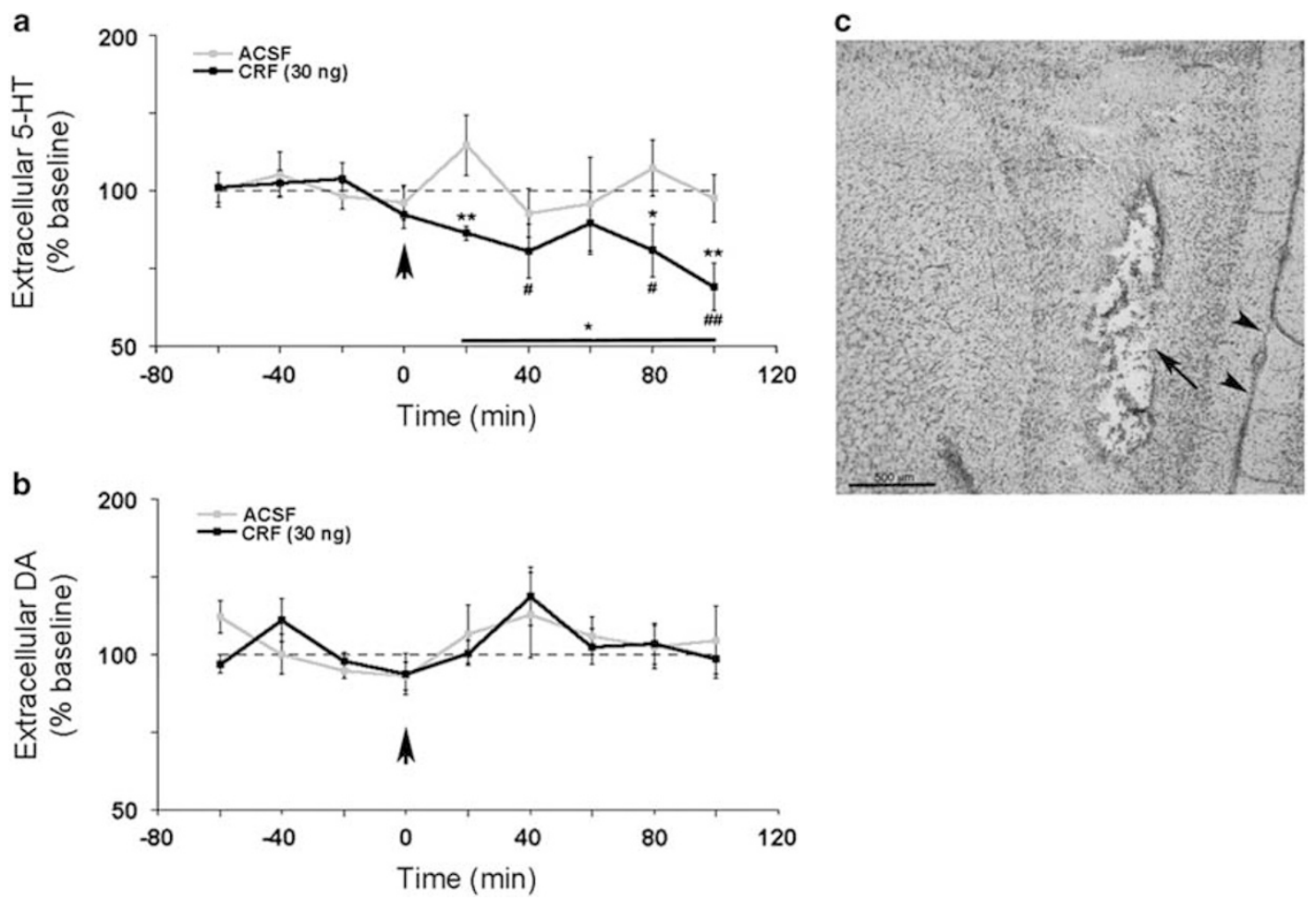

Figure 4 Intra-DRN CRF (30 ng) decreased mPFC 5-HT but not DA extracellular levels. (a) Effect of ACSF or CRF (30 ng) on mPFC 5-HT. The abscissa shows time $(\mathrm{min})$ before and after the infusion, which occurred at 0 . The ordinate indicates the extracellular level of 5-HT expressed as a percentage of baseline. The solid line above 20-100 min indicates a statistically significant effect of time for the CRF group based on the one-way ANOVA. (b) Effect of ACSF or CRF (30 ng) on mPFC DA in same rats as shown in a. The abscissa and ordinate are as described in a. Each point is the mean of six ACSF-treated rats and nine CRF-treated rats. Vertical lines indicate SEM. $* p<0.05, * * p<0.0$ I compared with ACSF; ${ }^{p}<0.05$, \#\# $p<0.01$ compared with baseline. (c) Photomicrograph of a representative section through the $\mathrm{mPFC}$ showing the placement of the microdialysis probe. The arrow points to the tract and the arrowheads point to the medial longitudinal fissure. ACSF, artificial cerebrospinal fluid; ANOVA, analysis of variance; CRF, corticotropin-releasing factor; DA, dopamine; DRN, dorsal raphe nucleus; mPFC, medial prefrontal cortex. 

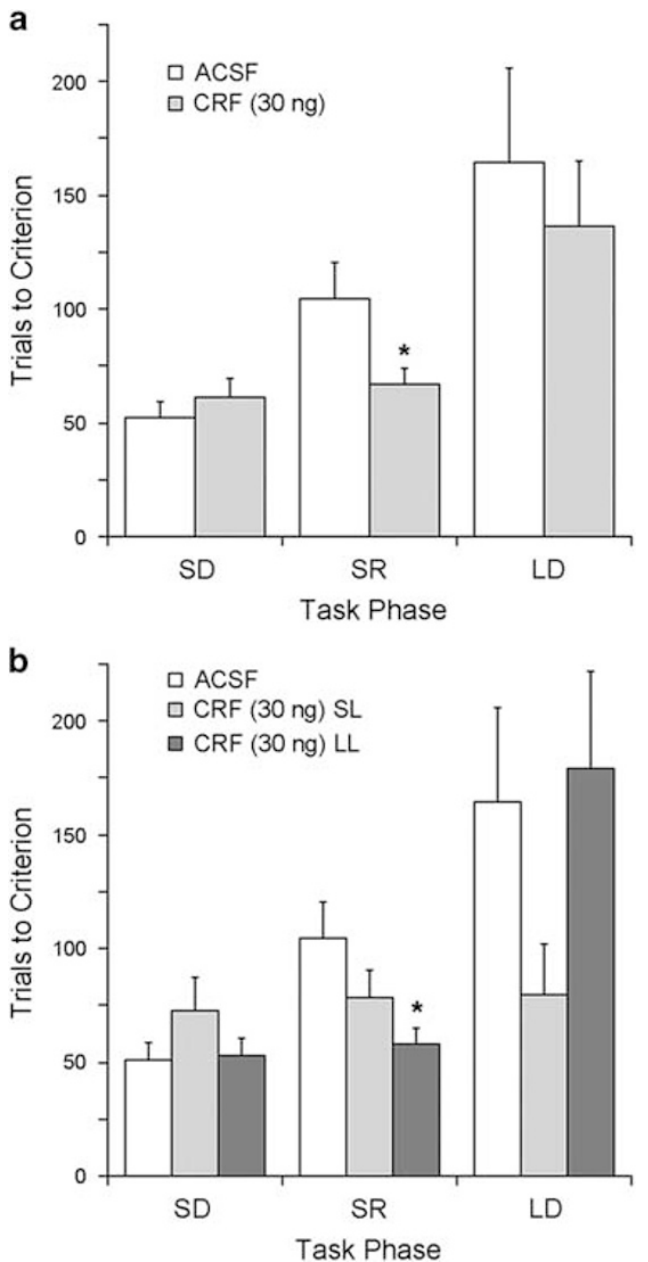

Figure 5 Prior social stress changes the impact of CRF on cognitive flexibility and this is dependent on coping style. (a) Comparison of task performance of rats exposed to social defeat that were administered ACSF $(n=9)$ or CRF $30 \mathrm{ng}(n=14)$ into the DRN. Task performance is indicated by the number of trials to reach criterion. Vertical lines indicated SEM. (b) CRF-treated rats were further analyzed by comparing effects with respect to whether they exhibited defeat within a short latency $(S L, n=6)$ or long latency $(L L, n=8)$. $* p<0.05$. ACSF, artificial cerebrospinal fluid; $C R F$, corticotropin-releasing factor; DRN, dorsal raphe nucleus.

by CRF in the DRN is mediated by $\mathrm{CRF}_{1}$ (Lukkes et al, 2008; Price and Lucki, 2001). The relatively long duration of CRF action is similar to that reported for other behaviors including burying behavior and potentiation of acoustic startle (Howard et al, 2008; Liang et al, 1992). This may be attributed to the engagement of signaling pathways that have enduring effects.

Whether the facilitation of strategy set-shifting is directly related to $\mathrm{CRF}_{1}$-induced changes in $5-\mathrm{HT}$ in the mPFC is unknown. Lesion and pharmacological studies implicate 5HT in reversal learning but not attentional set shifting (Boulougouris and Tsaltas, 2008; Homberg, 2012). For example, 5-HT depletion in the marmoset prefrontal cortex impaired reversal learning but not attentional set shifting (Clarke et al, 2005). $\mathrm{CRF}_{1}$-induced changes in 5-HT function in other brain regions could indirectly impact on processes underlying strategy set shifting. Importantly, the results suggest that an acute stress that would engage $\mathrm{CRF}_{1}$ receptors in the DRN can facilitate cognitive flexibility through enhanced strategy shifting. These CRF actions may play a role in the promotion of escape behavior and the ability of $\mathrm{CRF}_{1}$ receptor activation in the DRN to inhibit learned helplessness (Hammack et al, 2003a).

\section{Social Stress Experience Alters the Cognitive Impact of Intra-DRN CRF: Relation to Coping Strategy}

The response of DRN-5-HT neurons to CRF is qualitatively altered by a history of stress as a result of CRF receptor redistribution in DRN neurons. For example, prior swim stress induces the recruitment of $\mathrm{CRF}_{2}$ receptors from the cytoplasm to the plasma membrane and tends to promote $\mathrm{CRF}_{1}$ internalization (Waselus et al, 2009). This qualitatively changes the response to $\mathrm{CRF}$ from a $\mathrm{CRF}_{1}$-mediated inhibition to a $\mathrm{CRF}_{2}$-mediated excitation. The social stress used in the present study similarly induces $\mathrm{CRF}_{2}$ recruitment to the plasma membrane and $\mathrm{CRF}_{1}$ internalization, shifting DRN-5-HT neuronal responses to CRF from inhibition to $\mathrm{CRF}_{2}$-mediated excitation (Wood et al, 2013). Notably, these cellular changes were limited to the subpopulation of rats that exhibit a coping style characterized by a resistance to assume the defeat posture (LL rats). The present study provided evidence that social stress-induced changes in CRF function at the cellular level translate to changes in cognitive performance. Thus, in LL rats, CRF-induced facilitation of strategy set-shifting performance was replaced by an alternate form of cognitive flexibility, an improvement in reversal learning. This functional shift from enhanced strategy shifting to enhanced reversal learning is consistent with the cellular shift toward greater $\mathrm{CRF}_{2}$ regulation of DRN-5-HT transmission and the positive role of 5-HT in reversal learning. Reversal learning is improved by manipulations that elevate extracellular 5-HT such as genetic or pharmacological inhibition of the 5-HT transporter (Brigman et al, 2010). Conversely, 5-HT deficits as a result of lesions or dietary tryptophan removal impairs reversal learning (Clarke et al, 2005; Park et al, 1994). In addition, 5$\mathrm{HT}_{2 \mathrm{~A}}$ antagonists impair reversal learning, although antagonists of $5-\mathrm{HT}_{2 \mathrm{C}}$ and $5-\mathrm{HT}_{6}$ improve reversal learning (Boulougouris et al, 2008; Furr et al, 2012; Hatcher et al, 2005). Interesting, most of these manipulations affect the perseverative aspects of reversal learning, suggesting an effect on inhibition of a prior learned response. The improvement in reversal learning produced by CRF in stressed rats was associated with a decrease in regressive errors, implying enhanced learning and maintenance of a new rule rather than inhibition of a previously learned rule. Notably, swim stress, which alters DRN-5-HT neurotransmission through CRF (Price et al, 2002), also facilitates reversal learning and this improvement is apparent later in the task when errors would be regressive rather than perseverative (Graybeal et al, 2011).

The present study was designed as separate experiments in unstressed and stressed groups of rats because of the necessity to generate the CRF dose-response curve in stress-naive rats. Although this may not be optimal to analyze the effects of stress, the treatment differences in stressed rats were robust and consistent with stress-induced cellular changes. Stress-related enhancement of reversal learning has been previously demonstrated with swim stress 
and restraint as the stressors (Graybeal et al, 2011, 2014; Thai et al, 2013). It has been hypothesized that stress-induced deficits in ventromedial prefrontal cortical function allow for learning by alternate systems that are biased toward reversal learning as opposed to strategy shifting, although both are forms of cognitive flexibility (Graybeal et al, 2011). The present results suggest that social stress history and coping strategy interact with CRF in the DRN to direct this alternation in forms of cognitive flexibility.

\section{Clinical Implications}

The ability of moderate levels of CRF in the DRN to facilitate strategy set-shifting in the present study is reminiscent of the improvement of attention set shifting by similar levels of CRF in the LC (Snyder et al, 2012). Together the results suggest that acute stress can facilitate this form of cognitive flexibility through parallel actions of CRF in the LC and DRN and this is an adaptive cognitive response to the stressor. Although chronic and repeated stressors are thought to impair cognitive flexibility, the present results, taken with other studies, suggest that they may promote alternative forms of cognitive flexibility such as reversal learning. CRF-related plasticity in the DRN may be one mechanism for this shift. The finding that this adaptation is most apparent in the LL subpopulation, the population that is relatively resistant to developing depression-related endocrine, behavioral and cardiovascular endpoints suggests links between coping style and the cognitive consequences of stress (Wood et al, 2010, 2012).

\section{FUNDING AND DISCLOSURE}

This work was supported by PHS grants R01 MH058250 and T32MH14654. The authors declare no conflict of interests.

\section{ACKNOWLEDGMENTS}

We wish to acknowledge the technical assistance of Mr Mark Barry and Mr Andrew Ho.

\section{REFERENCES}

Amat J, Tamblyn JP, Paul ED, Bland ST, Amat P, Foster AC et al (2004). Microinjection of urocortin 2 into the dorsal raphe nucleus activates serotonergic neurons and increases extracellular serotonin in the basolateral amygdala. Neuroscience 129: 509-519.

Andrews CM, Lucki I (2001). Effects of cocaine on extracellular dopamine and serotonin levels in the nucleus accumbens. Psychopharmacology 155: 221-229.

Boulougouris V, Tsaltas E (2008). Serotonergic and dopaminergic modulation of attentional processes. Prog Brain Res 172: 517-542.

Boulougouris V, Glennon JC, Robbins TW (2008). Dissociable effects of selective 5-HT2A and 5-HT2C receptor antagonists on serial spatial reversal learning in rats. Neuropsychopharmacology 33: 2007-2019.

Brigman JL, Mathur P, Harvey-White J, Izquierdo A, Saksida LM, Bussey TJ et al (2010). Pharmacological or genetic inactivation of the serotonin transporter improves reversal learning in mice. Cereb Cortex 20: 1955-1963.

Clarke HF, Dalley JW, Crofts HS, Robbins TW, Roberts AC (2004). Cognitive inflexibility after prefrontal serotonin depletion. Science 304: $878-880$.
Clarke HF, Walker SC, Crofts HS, Dalley JW, Robbins TW, Roberts AC (2005). Prefrontal serotonin depletion affects reversal learning but not attentional set shifting. J Neurosci 25: 532-538.

Day HE, Greenwood BN, Hammack SE, Watkins LR, Fleshner M, Maier SF et al (2004). Differential expression of 5HT-1A, alpha 1b adrenergic, CRF-R1, and CRF-R2 receptor mRNA in serotonergic, gamma-aminobutyric acidergic, and catecholaminergic cells of the rat dorsal raphe nucleus. J Comp Neurol 474: 364-378.

Floresco SB, Block AE, Tse MT (2008). Inactivation of the medial prefrontal cortex of the rat impairs strategy set-shifting, but not reversal learning, using a novel, automated procedure. Behav Brain Res 190: 85-96.

Forster GL, Pringle RB, Mouw NJ, Vuong SM, Watt MJ, Burke AR et al (2008). Corticotropin-releasing factor in the dorsal raphe nucleus increases medial prefrontal cortical serotonin via type 2 receptors and median raphe nucleus activity. Eur J Neurosci 28: 299-310.

Fox JH, Lowry CA (2013). Corticotropin-releasing factor-related peptides, serotonergic systems, and emotional behavior. Front Neurosci 7: 169.

Furr A, Lapiz-Bluhm MD, Morilak DA (2012). 5-HT2A receptors in the orbitofrontal cortex facilitate reversal learning and contribute to the beneficial cognitive effects of chronic citalopram treatment in rats. Int J Neuropsychopharmacol 15: 1295-1305.

Gold PW, Chrousos GP (2002). Organization of the stress system and its dysregulation in melancholic and atypical depression: high vs low CRH/NE states. Mol Psychiatry 7: 254-275.

Graybeal C, Feyder M, Schulman E, Saksida LM, Bussey TJ, Brigman JL et al (2011). Paradoxical reversal learning enhancement by stress or prefrontal cortical damage: rescue with BDNF. Nat Neurosci 14: 1507-1509.

Graybeal C, Bachu M, Mozhui K, Saksida LM, Bussey TJ, Sagalyn E et al (2014). Strains and stressors: an analysis of touchscreen learning in genetically diverse mouse strains. PLoS One 9: e87745.

Hammack SE, Pepin JL, DesMarteau JS, Watkins LR, Maier SF (2003a). Low doses of corticotropin-releasing hormone injected into the dorsal raphe nucleus block the behavioral consequences of uncontrollable stress. Behav Brain Res 147: 55-64.

Hammack SE, Richey KJ, Schmid MJ, LoPresti ML, Watkins LR, Maier SF (2002). The role of corticotropin-releasing hormone in the dorsal raphe nucleus in mediating the behavioral consequences of uncontrollable stress. J Neurosci 22: 1020-1026.

Hammack SE, Schmid MJ, LoPresti ML, Der-Avakian A, Pellymounter MA, Foster AC et al (2003b). Corticotropin-releasing hormone type 2 receptors in the dorsal raphe nucleus mediate the behavioral consequences of uncontrollable stress. J Neurosci 23: 1019-1025.

Hatcher PD, Brown VJ, Tait DS, Bate S, Overend P, Hagan JJ et al (2005). 5-HT6 receptor antagonists improve performance in an attentional set shifting task in rats. Psychopharmacology (Berl) 181: 253-259.

Hauger RL, Grigoriadis DE, Dallman MF, Plotsky PM, Vale WW, Dautzenberg FM (2003). International Union of Pharmacology. XXXVI. Current status of the nomenclature for receptors for corticotropin-releasing factor and their ligands. Pharmacol Rev 55: $21-26$.

Homberg JR (2012). Serotonin and decision making processes. Neurosci Biobehav Rev 36: 218-236.

Howard O, Carr GV, Hill TE, Valentino RJ, Lucki I (2008). Differential blockade of CRF-evoked behaviors by depletion of norepinephrine and serotonin in rats. Psychopharmacology (Berl) 199: $569-582$.

Kessler RC (1997). The effects of stressful life events on depression. Annu Rev Psychol 48: 191-214.

Kirby LG, Rice K, Valentino RJ (2000). Effects of corticotropinreleasing factor on neuronal activity in the serotonergic dorsal raphe nucleus. Neuropsychopharmacology 22: 148-162. 
Kirby LG, Chou-Green JM, Davis K, Lucki I (1997). The effects of different stressors on extracellular 5-hydroxytryptamine and 5hydroxyindoleacetic acid. Brain Res 760: 218-230.

Kirby LG, Freeman-Daniels E, Lemos JC, Nunan JD, Lamy C, Akanwa A et al (2008). Corticotropin-releasing factor increases GABA synaptic activity and induces inward current in 5hydroxytryptamine dorsal raphe neurons. J Neurosci 28: 12927-12937.

Liang KC, Melia KR, Miserendino MJD, Falls WA, Campeau S, Davis M (1992). Corticotropin-releasing factor: Long-lasting facilitation of the acoustic startle reflex. J Neurosci 12: 2303-2312.

Lukkes JL, Forster GL, Renner KJ, Summers CH (2008). Corticotropin-releasing factor 1 and 2 receptors in the dorsal raphe differentially affect serotonin release in the nucleus accumbens. Eur J Pharmacol 578: 185-193.

Maier SF, Watkins LR (2005). Stressor controllability and learned helplessness: the roles of the dorsal raphe nucleus, serotonin, and corticotropin-releasing factor. Neurosci Biobehav Rev 29: 829-841.

McEwen BS (2003). Mood disorders and allostatic load. Biol Psychiatry 54: 200-207.

Meloni EG, Reedy CL, Cohen BM, Carlezon WA Jr (2008). Activation of raphe efferents to the medial prefrontal cortex by corticotropin-releasing factor: correlation with anxiety-like behavior. Biol Psychiatry 63: 832-839.

Miczek KA (1979). A new test for aggression in rats without aversive stimulation: differential effects of d-amphetamine and cocaine. Psychopharmacology (Berl) 60: 253-259.

Park SB, Coull JT, McShane RH, Young AH, Sahakian BJ, Robbins TW et al (1994). Tryptophan depletion in normal volunteers produces selective impairments in learning and memory. Neuropharmacology 33: 575-588.

Paxinos G, Watson C (1998). The Rat Brain in Stereotaxic Coordinates. Academic Press: North Ryde, NSW, Australia.

Pernar L, Curtis AL, Vale WW, Rivier JE, Valentino RJ (2004). Selective activation of corticotropin-releasing factor-2 receptors on neurochemically identifed neurons in the rat dorsal raphe nucleus reveals dual actions. J Neurosci 24: 1305-1311.

Price ML, Lucki I (2001). Regulation of serotonin release in the lateral septum and striatum by corticotropin-releasing factor. J Neurosci 21: 2833-2841.

Price ML, Kirby LG, Valentino RJ, Lucki I (2002). Evidence for corticotropin-releasing factor regulation of serotonin in the lateral septum during acute swim stress: adaptation produced by repeated swim. Psychopharmacology 162: 406-414.
Reyes TM, Lewis K, Perrin MH, Kunitake KS, Vaughan J, Arias CA et al (2001). Urocortin II: a member of the corticotropin-releasing factor (CRF) neuropeptide family that is selectively bound by type 2 CRF receptors. Proc Natl Acad Sci USA 98: 2843-2848.

Roche M, Commons KG, Peoples A, Valentino RJ (2003). Circuitry underlying regulation of the serotonergic system by swim stress. J Neurosci 23: 970-977.

Snyder K, Wang WW, Han R, McFadden K, Valentino RJ (2012). Corticotropin-releasing factor in the norepinephrine nucleus, locus coeruleus, facilitates behavioral flexibility. Neuropsychopharmacology 37: 520-530.

Snyder KP, Barry M, Valentino RJ (2014). Cognitive impact of social stress and coping strategy throughout development. Psychopharmacology 232: 185-195.

Thai CA, Zhang Y, Howland JG (2013). Effects of acute restraint stress on set-shifting and reversal learning in male rats. Cogn Affect Behav Neurosci 13: 164-173.

Valentino RJ, Commons KG (2005). Peptides that fine-tune the serotonin system. Neuropeptides 39: 1-8.

Valentino RJ, Van Bockstaele E (2008). Convergent regulation of locus coeruleus activity as an adaptive response to stress. Eur J Pharmacol 583: 194-203.

Valentino RJ, Liouterman L, Van Bockstaele EJ (2001). Evidence for regional heterogeneity in corticotropin-releasing factor interactions in the dorsal raphe nucleus. J Comp Neurol 435: 450-463.

Waselus M, Valentino RJ, Van Bockstaele EJ (2005). Ultrastructural evidence for a role of gamma-aminobutyric acid in mediating the effects of corticotropin-releasing factor on the rat dorsal raphe serotonin system. J Comp Neurol 482: 155-165.

Waselus M, Nazzaro C, Valentino RJ, Van Bockstaele EJ (2009). Stress-induced redistribution of corticotropin-releasing factor receptor subtypes in the dorsal raphe nucleus. Biol Psychiatry 66: $76-83$.

Wood SK, Walker HE, Valentino RJ, Bhatnagar S (2010). Individual differences in reactivity to social stress predict susceptibility and resilience to a depressive phenotype: role of corticotropinreleasing factor. Endocrinology 151: 1795-1805.

Wood SK, McFadden KV, Grigoriadis D, Bhatnagar S, Valentino RJ (2012). Depressive and cardiovascular disease comorbidity in a rat model of social stress: a putative role for corticotropinreleasing factor. Psychopharmacology (Berl) 222: 325-336.

Wood SK, Zhang XY, Reyes BA, Lee CS, Van Bockstaele EJ, Valentino RJ (2013). Cellular adaptations of dorsal raphe serotonin neurons associated with the development of active coping in response to social stress. Biol Psychiatry 73: 1087-1094.

Supplementary Information accompanies the paper on the Neuropsychopharmacology website (http://www.nature.com/npp) 